\title{
Total Laparoscopic Hysterectomy Outcomes for Large Uterus (>14 Weeks) Due to Large and Multiple Fibroids
}

\author{
(D) Betül YAKIŞTIRANa, \\ (D) Yavuz Emre ŞÜKÜR \\ Bülent BERKER ${ }^{b}$, \\ Salih TAŞKIN \\ Batuhan ÖZMEN \\ (D) Murat SÖNMEZER ${ }^{b}$ \\ D Cem Somer ATABEKOĞLUb \\ ${ }^{a}$ Clinic of Obstetrics and Gynecology, \\ Ankara Zekai Tahir Burak Women's \\ Health Teaching and Research Hospital, \\ 'Department of Obstetrics and Gynecology, \\ Ankara University Faculty of Medicine, \\ Ankara, TURKEY
}

Received: 31 Jul 2019

Received in revised form: 09 Oct 2019

Accepted: 15 Oct 2019

Available online: 22 Oct 2019

Correspondence:

Betül YAKIŞTIRAN

Ankara Zekai Tahir Burak Women's

Health Teaching and Research Hospital,

Clinic of Obstetrics and Gynecology,

Ankara, TURKEY

btlengin@gmail.com

This text was presented as a poster at the $26^{\text {th }}$ European Society for Gynecological Endoscopy (ESGE) Congress 18-21 October 2017, at Sueno Hotel Belek \& Convention Center, Antalya, Turkey.

Copyright ( 2019 by Türkiye Klinikleri

\begin{abstract}
Objective: Total laparoscopic hysterectomy (TLH) seems to be the best surgical route for most cases. However, the technical difficulties, while removing a large uterus due to huge fibroids should be noted. The aim of this study was to assess the effect of large uterine size ( $>14$ weeks) due to large fibroids on the outcome of TLH. Material and Methods: A total of 234 TLH cases were included in the study. The study group consisted of the patients with clinical size $>14$ gestational weeks uterus $(\mathrm{n}=99)$. The control group consisted of patients with smaller uterine size and operated with benign indications $(\mathrm{n}=135)$. The groups were comparable regarding body mass index, comorbidities, and previous abdominal surgery. Results: The mean duration of operation, estimated blood loss and the rates of complications were similar between the groups. The rate of conversion to laparotomy did not show a statistically significant difference between the groups. There were five conversions in the study group due to excessive bleeding $(\mathrm{n}=2)$, inability to mobilize the uterus $(\mathrm{n}=2)$, and intestinal injury $(\mathrm{n}=1)$. The two conversions in the control group were also due to excessive bleeding. Conclusion: Total laparoscopic hysterectomy for large uterine size $>14$ weeks size due to large fibroids seems to be a safe and successful surgical approach.
\end{abstract}

Keywords: Conversion; complication; large uterus; total laparoscopic hysterectomy

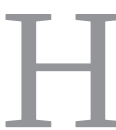
ysterectomy is one of the most frequent gynecologic surgeries. Of benign reasons, symptomatic uterine fibroids and pelvic organ prolapse are the two most common reasons for hysterectomy. ${ }^{1}$ In women who have a large fibroid and not seeking pregnancy, hysterectomy is usually preferred. ${ }^{2}$ Three choices available to the surgeon are the abdominal, vaginal and total laparoscopic hysterectomy (TLH). Several factors are associated with the decision of surgical route. In order to choose the perfect method, the surgeon should take into consideration how the procedure can be performed most safely to fulfill the needs of the patient.

The ratio of endoscopic hysterectomies has increased significantly over the last two decades. Surgeons prefer endoscopic procedures due to their significant advantages such as shorter hospital stay, faster recovery time, less blood loss, better patient satisfaction and less infection risk. ${ }^{3,4}$ Today, TLH seems to be the best surgical route for most of the cases with the improvements in minimally invasive techniques. However, the technical difficulties, regardless of the surgical route, while removing a large uterus due to huge fibroids should be noted.

In literature, various studies have demonstrated the advantages of minimally invasive surgeries for most gynecological conditions. ${ }^{3}$ Large uterus 
due to large or multiple fibroids might be challenging for all types of surgical routes. During laparoscopic approach, large fibroids can obscure the surrounding anatomical structures, prevent mobilization of the uterus, obstruct visualization especially during ligation of uterine arteries. However, there's no clear data regarding the surgical route for large uteri. In addition to the well- known benefits of the laparoscopic surgeries, access to anatomical planes becomes easier with the advantage of magnified vision. Although laparotomy for large uteri is a common practice worldwide, TLH is increasingly preferred by experienced centers. But, there's no certain recommendation for the surgical route for hysterectomy of large uteri and the cutoff uterine size for decision making. Hence, seeking for limits of TLH for large uteri continues.

The aim of this study was to evaluate the effect of large uterine size due to multiple fibroids on the outcome of TLH operation.

\section{MATERIAL AND METHODS}

In the present single center retrospective cohort study the data of all women who underwent TLH for benign conditions at the Department of Obstetrics and Gynecology, Ankara University School of Medicine from January 2011 to January 2017 were reviewed. The study was approved by the Institutional Review Board (12405952/17.06.2016). All procedures performed were in accordance with the ethical standards of the institutional review board and with the Helsinki declaration or comparable ethical standards.

Variables including age, body mass index $\left(\mathrm{BMI}-\mathrm{kg} / \mathrm{m}^{2}\right)$, presence of systemic diseases, additional surgical intervention, additional bilateral salphingo-oophorectomy (BSO), operation time (minutes), duration of hospital stay (day), postoperative hemoglobin drop (g/dl), estimated blood loss (ml), intraoperative or postoperative major complications, need of blood transfusion were recorded from patient files.

The clinical uterine size assessment by bimanual examination has been shown to be the best way to estimate uterine weight. ${ }^{5}$ In our daily practice, we assess the uterine size by both bimanual examination and ultrasound measurements. In the present study, we used the cut-off value of 14 weeks for clinical size which corresponds to approximately 300-350 g. ${ }^{6}$ The study group consisted of the patients with clinical size $>14$ gestational weeks uterus $(n=99)$ and the control group consisted of the patients with smaller uterine size and operated with benign indications such as endometrial pathology or smaller fibroids $(\mathrm{n}=135)$. The exclusion criteria were body mass index $(\mathrm{BMI})>35$, age $>65$, patients at a high anaesthesiological risk (ASA $>$ III). Women were excluded if there was preoperative and postoperative diagnosis of malignancy.

All patients in both groups had a preoperative evaluation that included medical history, physical examination, transvaginal ultrasound, and basic blood investigations. On preoperative preparation, written informed consent was obtained from all patients. All TLH procedures were performed by senior gynecologists experienced more than 10 years on laparoscopic surgery. The decision of performing BSO were made by the surgeons according to menopausal status of the patients and inspection of both ovaries. Additional surgical interventions included any procedure other than BSO (lysis of adhesions and appendectomy etc.). The operation time was calculated from the first skin incision to the last skin-closure suture. Estimated blood loss was measured from the content of the suction bag. The length of hospital stay was calculated from the preoperative admission day to discharge from hospital. We evaluated postoperative complications by using the Clavien-Dindo Classifications system. ${ }^{6,7}$

All of the TLH procedures were performed by the same basic steps. Under general anesthesia, uterine manipulator (Vcare ${ }^{\circledR}$, CONMED, USA) was inserted through cervix after placing the Foley catheter into the bladder in Trendelenburg position. Then, pneumoperitoneum was created by CO2. Total laparoscopic hysterectomy was performed by mainly using advanced bipolar device (Ligasure $^{\mathrm{tm}}$, Valleylab, USA). After the coagulation and cutting of infundibulopelvic or ovarian ligaments and round ligaments, the retroperitoneum was entered and ureters were visualized. Then, 
bladder peritoneum was dissected from cervix, and bilateral uterine arteries were sealed and cut. The cardinal and sacrouterine ligaments were coagulated and transected. Finally, circumferential colpotomy was made by using monopolar energy and vaginal cuff was closed through laparoscopy by interrupted No.1 vicryl sutures. All specimens were removed directly or by cutting with lancet through vagina.

The main outcome parameters were duration of hospital stay and major complication rates. The other evaluated parameters included demographic characteristics such as age, BMI, co-morbidities, previous surgery and preoperative hemoglobin, and intra- and post- operative data such as operation time, estimated blood loss, duration of hospital stay and complications.

\section{STATISTICAL ANALYSIS}

Data analyses were performed by using SPSS Version 21.0 (IBM Corporation, Armonk, NYC, USA). Shapiro-Wilk test was used to test distribution of normality. Differences between groups for categorical variables were analyzed by chi-square test and the comparisons of continuous variables between groups were analyzed by Student's t test according to the results of their normality tests. $\mathrm{P}$ value less than 0.05 was considered statistically significant.

\section{RESULTS}

A total of 234 patients, 99 in the study group and 135 in the control group were included in the final analyses. The study and control groups were comparable regarding demographics except age and preoperative hemoglobin levels (Table 1). The mean ages of the study and control groups were $48.6 \pm 5.4$ and $51.8 \pm 9.1$ years, respectively $(\mathrm{p}=0.003)$. The preoperative hemoglobin levels of study and control groups were $12.1 \pm 1.6$ and $12.6 \pm 1.5 \mathrm{~g} / \mathrm{dl}$, respectively $(\mathrm{p}=0.010)$.

The outcome parameters are represented in Table 2 . There were no statistically significant differences between the groups regarding operation time, estimated blood loss, duration of hospital stays, and major complication rates. There were two major complications in the study group (one intestinal injury and one vaginal cuff dehiscence) and one major complication in the control group (bladder injury). The rate of conversion to laparotomy did not show a statistically significant difference between the groups. There were five conversions in the study group due to excessive bleeding $(\mathrm{n}=2)$, inability to mobilize the uterus $(\mathrm{n}=2)$, and intestinal injury $(\mathrm{n}=1)$. The two conversions in the control group were also due to excessive bleeding.

\begin{tabular}{|c|c|c|c|}
\hline & Study group (n:99) & Control group (n:135) & $p$ \\
\hline Age, years & $48.6 \pm 5.4$ & $51.8 \pm 9.1$ & 0,003 \\
\hline $\mathrm{BMl}, \mathrm{kg} / \mathrm{m}^{2}$ & $28.3 \pm 4.3$ & $28.6 \pm 3.6$ & 0,575 \\
\hline Co-morbidities, n (\%) & $43(37.7)$ & $71(62.3)$ & 0,187 \\
\hline Previous surgery, $n(\%)$ & $36(36.4)$ & $38(28.1)$ & 0,182 \\
\hline Preoperative hemoglobin, g/dL & $12.1 \pm 1.6$ & $12.6 \pm 1.5$ & 0,010 \\
\hline
\end{tabular}

BMI: Body mass index.

\begin{tabular}{|c|c|c|c|}
\hline & Study group (n:99) & Control group (n:135) & $p$ \\
\hline Operation time, minutes & $91.5 \pm 30.3$ & $93.0 \pm 30.6$ & 0,716 \\
\hline Estimated blood loss, $\mathrm{mL}$ & $191.9 \pm 108.2$ & $193.0 \pm 106.3$ & 0,937 \\
\hline Hospital stay, days & $3.0 \pm 1.8$ & $2.8 \pm 1.7$ & 0,572 \\
\hline Major complications, $n(\%)$ & $2(2)$ & $1(0.7)$ & 0,575 \\
\hline Conversion to laparatomy, $n(\%)$ & $5(5)$ & $2(1.4)$ & 0,136 \\
\hline
\end{tabular}




\section{DISCUSSION}

In our study, we assessed the effects of large uterine size due to single large fibroid or multiple fibroids ( $>14$ weeks size) on the intra- and post-operative outcome of TLH. According to our findings, large uterine size does not affect unfavorably the outcome of TLH. The operation time, major complication rate and conversion rate of patients with large uterine size were comparable to those with smaller uterine size.

Large uterus has been classified by uterine weight and/or size and various cut-off values have been identified. ${ }^{3,8,9}$ Previous literature recommended TLH for uterus less than 15 weeks size or $500 \mathrm{~g}^{3}$ However, in a recent study Ucella et al. defined large uterus as heavier than $1 \mathrm{~kg} .{ }^{8}$ In another one, Sinha et al. defined as larger than 16 weeks size. ${ }^{9}$ With the passing of time the definition of large uterus has changed quickly due to increasing experience in endoscopic surgery. Few studies have investigated differences related to uterine weight between abdominal and laparoscopic surgeries. ${ }^{8,10,11}$ Also, some cases were reported for very large uterus with huge fibroids. ${ }^{2,12}$ However, we believe in that reporting preoperative uterine size estimation is better. Although we can use some charts to estimate uterine weight, we cannot measure it exactly before operation. Also, we believe in that clinical uterine size assessment by gestational weeks and ultrasound measurements prior to surgery is a more objective estimation of large uterus which can affect the destiny of surgery. Large uterus has some limitations in TLH due to remaining insufficient intraabdominal space, and technical difficulties in accessing to correct pelvic anatomic planes. The most important risks of these limitations are bladder or bowel injuries and excessive hemorrhage.

In a recent trial Terzi et al. investigated the factors affecting TLH outcome and accepted operation time as the critical end-point which was 70 minutes in median. ${ }^{11}$ The authors found uterine weight 300 $\mathrm{g}$ as the cut-off for longer operation time by using receiver operating characteristic curve analysis. ${ }^{11}$ Similar to that one Wattiez et al. took $300 \mathrm{~g}$ as cutoff value and reported longer operating time in women with enlarged uteri than in women with smaller uteri (156 $\pm 50 \mathrm{~min}$. vs. $108 \pm 35 \mathrm{~min}$., respectively; $\mathrm{p}<0.001) .{ }^{13}$ Sinha et al. reported the median operative time as 107 minutes in their TLH series for large uteri (mean size $17.5 \pm 2$ weeks). ${ }^{9}$ Similar to that Uccella et al. reported 120 minutes of median operation time in large uteri weighing $>1 \mathrm{~kg} .{ }^{8}$ Our results regarding operation time showed no significant difference between large uteri and controls. The operation time was approximately 90 minutes which placed in between the aforementioned studies. Although we failed to show a significant difference regarding operation time, we should point out that some very large uteri need cold knife morcellation through vagina and this procedure can significantly prolong the operation time.

Previous studies reported different complication rates with various definitions. O'Hanlan et al. found no correlation between uterine size and postoperative complication rate. ${ }^{14}$ They reported total complication rate as $9.9 \%$ and major complication rate requiring re-operation as $5.2 \%{ }^{14}$ Terzi et al. reported the total complication rate as $9.92 \%$ and they also failed to show a significant impact of uterine weight on complication rate ( $<300 \mathrm{~g}: 10.83 \%$ vs. $>300$ g: 9.26\%). ${ }^{11}$ Previous studies reported approximately $10 \%$ total complication rate in TLH for large uteri. ${ }^{8,10,13}$ However, two recent studies reported major complication rates. Sinha et al. reported intraoperative major complication rate of $2.3 \% .{ }^{9} \mathrm{Uc}-$ cella et al. reported a total of nine significant complications (4.4\%) among TLH for 203 women with large uteri. ${ }^{8}$ Our results are in consistency with previous literature and we also failed to show a significant effect of uterine size on major complication rate. However, the similar complication rates both in our study and previous studies might be related to the experience of the surgeon and the center.

Total laparoscopic hysterectomy for large uterus is a challenging surgical procedure and conversion to laparotomy is reasonable in some cases. Hemorrhage and organ injuries due to limited space for operation can necessitate conversion to laparotomy. Main reasons of the conversion to laparotomy are described as excessive hemorrhage and bladder injuries. ${ }^{9}$ Previous studies reported 
conversion rates between $1.7 \%$ and $17.4 \%$ due to inadequate space and size of uterus..$^{8,11,15}$ The wide range between different studies is possibly due to varying definitions of large uterus. The conversion rate in our large uterus group (5\%) was reasonable and similar to that of the control group.

Several authors suggested higher insertion point for the first port to provide sufficient visualization and to minimize the risk of uterine laceration. ${ }^{2,8,13,16,17}$ Although the place of first port varies in the literature, it's generally placed approximately $8 \mathrm{~cm}$ higher than the fundus. ${ }^{2,17}$ In our clinic, we also prefer to place the first port higher in case of extremely large uterus. We generally place the first camera port $3-4 \mathrm{~cm}$ above umbilicus according to the primary surgeon's decision.

The strengths of our study are homogenous and large sample of subjects and the consistency of the same surgical team during the study period. The main limitation of our study was its retrospective design. Also, surgical details such as postoperative uterine weight were not measured in most of the cases. However, we believe in that preoperative clinical uterine size estimation and ultrasound evaluation of fibroid size and number are more feasible measures to define a large uterus. Another point was the lack of late postoperative surgical complications and the lack of final pathology diagnosis. We recorded the pathology results to our data-chart as only 'benign'; because 'malignant' cases were excluded from the study.

\section{CONCLUSION}

In conclusion, total laparoscopic hysterectomy for large uteri $>14$ weeks size due to large and/or mul- tiple fibroids is a safe and successful surgical approach. The similar major complication and conversion rates, estimated blood loss and operative time in comparison with smaller controls suggest total laparoscopic hysterectomy as the first line surgical option in women with large uterus.

\section{Ethical Approval}

All procedures performed were in accordance with the ethical standards of the institutional review board and with the Helsinki declaration or comparable ethical standards.

\section{Source of Finance}

During this study, no financial or spiritual support was received neither from any pharmaceutical company that has a direct connection with the research subject, nor from a company that provides or produces medical instruments and materials which may negatively affect the evaluation process of this study.

\section{Conflict of Interest}

No conflicts of interest between the authors and / or family members of the scientific and medical committee members or members of the potential conflicts of interest, counseling, expertise, working conditions, share holding and similar situations in any firm.

\section{Authorship Contributions}

Idea/Concept: Yavuz Emre Şükür, Salih Taşkın, Bülent Berker; Design: Batuhan Özmen, Bülent Berker, Yavuz Emre Şükür, Cem Somer Atabekoğlu; Control/Supervision: Murat Sönmezer, Bülent Berker; Data Collection and/or Processing: Betül Yakıştıran, Yavuz Emre Şükür, Batuhan Özmen; Analysis and/or Interpretation: Cem Somer Atabekoğlu, Bülent Berker, Salih Taşkın; Literature Review: Betül Yakıştıran, Murat Sönmezer; Writing the Article: Betül Yakıştıran, Murat Sönmezer; Critical Review: Batuhan Özmen, Salih Taşkın; Materials: Betül Yakıştıran.

\section{REFERENCES}

1. Jacoby VL, Autry A, Jacobson G, Domush R, Nakagawa S, Jacoby A. Nationwide use of laparoscopic hysterectomy compared with abdominal and vaginal approaches. Obstet Gynecol. 2009;114(5):1041-8. [Crossref] [PubMed] [PMC]

2. Ceccaroni M, Roviglione G, Pesci A, Quintana S, Bruni F, Clarizia R. Total laparoscopic hysterectomy of very enlarged uterus $(3030 \mathrm{~g})$ : case report and review of the literature.
Wideochir Inne Tech Maloinwazyjine. 2014;9(2):302-7. [Crossref] [PubMed] [PMC]

3. Kluivers KB, Hendricks JC, Mol BW, Bongers MY, Bremer GL, de Vet HC, et al. Quality of life and surgical outcome after total laparoscopic hysterectomy versus total abdominal hysterectomy for benign disease: a randomized, controlled trial. J Minim Invasive Gynecol. 2007;14(2):145-52. [Crossref] [PubMed]
4. Kondo W, Bourdel N, Marengo F, Botchorishvili $R$, Pouly JL, Jardon $K$, et al. Is laparoscopic hysterectomy feasible for uteri larger than $1000 \mathrm{~g}$ ? Eur J Obstet Gynecol Reprod Biol. 2011;158(1):76-81. [Crossref] [PubMed]

5. Harb TS, Adam RA. Predicting uterine weight before hysterectomy: ultrasound measurements versus clinical assessment. Am J Obstet Gynecol. 2005;193(6):2122-5. [Crossref] [PubMed] 
6. Clavien PA, Barkun J, de Oliveira ML, Vauthey JN, Dindo D, Schulick RD, et al. The Clavien-Dindo classification of surgical complications: five-year experience. Ann Surg. 2009;250(2):187-96. [Crossref] [PubMed]

7. Dindo D, Demartines N, Clavien PA. Classification of surgical complications: a new proposal with evaluation in a cohort of 6336 patients and results of a survey. Ann Surg. 2004;240(2):205-13. [Crossref] [PubMed] [PMC]

8. Uccella S, Morosi C, Marconi N, Arrigo A, Gisone B, Casarin J, et al. Laparoscopic versus open hysterectomy for benign disease in uteri weighing $>1 \mathrm{~kg}$ : a retrospective analysis on 258 patients. J Minim Invasive Gynecol. 2018;25(1):62-9. [Crossref] [PubMed]

9. Sinha R, Swarnasree G, Rupa B, Madhumathi S. Laparoscopic hysterectomy for large uteri: outcomes and techniques. J Minim Access Surg. 2019;15(1):8-13. [Crossref] [PubMed] [PMC]
10. Ark C, Güngördük K, Celebi I, Celikkol O. Experience with laparoscopic-assisted vaginal hysterectomy for the enlarged uterus. Arch Gynecol Obstet. 2009;280(3):425-30. [Crossref] [PubMed]

11. Terzi H, Hasdemir PS, Biler A, Kale A, Sendag $F$. Evaluation of the surgical outcome and complications of total laparoscopic hysterectomy in patients with enlarged uteruses. Int J Surg. 2016;36(Pt A):90-5. [Crossref] [PubMed]

12. Nakayama $K$, Tsukao $M$, Ishikawa $M$, Ishibashi T, Nakamura K, Sanuki K, et al. Total laparoscopic hysterectomy for large uterine cervical myoma. Mol Clin Oncol. 2017;6(5):655-60. [Crossref] [PubMed] [PMC]

13. Wattiez $A$, Soriano D, Fiaccamento A, Canis M, Botchorishvill R, Pouly J, et al. Total laparoscopic hysterectomy for very enlarged uteri. J Am Assoc Gynecol Laparosc. 2002;9(2):125-30. [Crossref] [PubMed]
14. O'Hanlan KA, Dibble SL, Garnier AC, Reuland ML. Total laparoscopic hysterectomy: technique and complications of 830 cases. JSLS. 2007;11(1):45-53. [PubMed]

15. Schöller $D$, Taran FA, Wallwiener M, Schönfisch B, Krämer B, Abele H, et al. Laparoscopic supracervical hysterectomy and laparoscopic total hysterectomy in patients with very large uteri: a retrospective single- center experience at a major university hospital. Geburtshilfe Frauenheilkd. 2017;77(3): 251-6. [Crossref] [PubMed] [PMC]

16. Kehde BH, van Herendael BJ, Tas B, Jain D, Helsen $\mathrm{K}$, Jochems L. Large uterus: what is the limit for a laparoscopic approach? Autops Case Rep. 2016;6(1):51-6. [Crossref] [PubMed] [PMC]

17. Wu KY, Lertvikool S, Huang KG, Su H, Yen CF, Lee CL. Laparoscopic hysterectomies for large uteri. Taiwan J Obstet Gynecol. 2011;50(4):411-4. [Crossref] [PubMed] 